\section{Webcasting: casting the web more widely}

\author{
P. A. Reynolds, ${ }^{1}$ R. Mason ${ }^{2}$ and K. A. Eaton ${ }^{3}$
}

IN BRIEF

- Describes how web and podcasting have been and are being used in the delivery of dental education.

- These new techniques offer a range of benefits to both teachers and students and enable educational programmes to be delivered at any time and in any place.

- The paper indicates how these techniques will be used in both undergraduate and continuing dental education.

In the search for a cost-effective method of delivering teaching to dispersed groups of students, webcasting is proving successful. By taking video streams and transmitting them over the Internet it allows events such as lectures, seminars, webinars and tuition sessions to be made accessible to participants in many different, remote locations. Moreover, the webcasts can be stored on a normal PC to give, those unable to see the original broadcast, the opportunity to watch it at a later, more convenient time; similarly it can be used by students for revision purposes. New developments have allowed a useful level of interactivity between presenters and students, and between students themselves. As part of a recent project at a UK dental school, webcasting was trialed amongst undergraduates and postgraduates to measure its value for dental education. The results have been very encouraging, with the latter group especially benefiting from being able to see the webcasts in their own time, on their PCs at home or work. However, as befits an ever-changing scenario, a new web-oriented facility is beginning to play a role in education: podcasting provides a more personal, individual interaction with the web. ${ }^{1}$

\section{E-LEARNING IN DENTISTRY}

Section A: Teaching and technology

1. A description of the new technologies used in transforming dental education

2. Seeing is believing: dental education benefits from developments in videoconferencing

3. Webcasting: casting the web more widely

4. Top of the pops - CD-ROM and DVDs in dental education

Section B: Informatics: better informed

by systems and services

5. Better informed: an overview of health informatics

6. Better informed in clinical practice a brief overview of dental informatics

7. Digital clinical records and practice administration in primary dental care

Section C: Impact of e-learning in

dental education

8. Remember the days in the old school yard: from lectures to online learning

9. An intricate web - designing and authoring a web-based course

10. The many faces of interaction

11. Supporting the learner and teacher online

12. Making a mark - taking assessment to technology

13. Continuing professional development and ICT: target practice

14. Assuring quality

Section D: A connected future

15. Nine years of DentEd: a global perspective

16. A vision of dental education in the third millenium
Two of the key benefits of information communications technologies (ICT) for education are:

1. The ability to disseminate teaching material and information to a widely-dispersed student body

2. To allow students to have continual access to their learning environment irrespective of time and location.

The advent of webcasting (and now podcasting) has been a prime contributor to these developments as it allows events such as lectures and conferences to be transmitted from a central location to any number of end-points capable of receiving them, although some authors have argued that 'There is no substitute for being there to experience the look,

\footnotetext{
${ }^{1 *}$ Professor of Dental Education, Centre of Flexible Learning in Dentistry, King's College London Dental Institute, Floor 3, Strand Bridge House, 138-142 Strand, London, WC2 $1 \mathrm{HH}:{ }^{2}$ Professor of Educational Technology, Institute of Educational Technology, The Open University, Walton Hall, Milton Keynes, MK7 6AA; ${ }^{3}$ Visiting Professor, UCL Eastman Dental Institute, 256 Gray's Inn Road, London, WC1X 8LD

${ }^{*}$ Correspondence to: Professor P. A. Reynolds Email: P.A.Reynolds@kcl.ac.uk
}

\section{Refereed Paper}

DOI: $10.1038 /$ bdj.2008.55

${ }^{\circledR}$ British Dental Journal 2008; 204: 145-149 feel, excitement and overall sense of presence at an event.'2

\section{DEFINITION}

Webcasting has been defined as 'broadcast video, live or on-demand, using streaming technology across the World Wide Web... to offer the ability to deliver good quality imaging... within any chosen learning environment. ${ }^{3}$ It takes one source and places it on an IP network (the Internet) in quasi real-time to transmit to many end-points without stretching the network. The equipment that decodes the traffic does so by buffering the information. This takes approximately twelve seconds to achieve, which limits the interactive possibilities. However, as it uses the Internet, it is a very inexpensive method of delivering lectures and other online events to a much larger potential audience.

Webcasting is also known as streaming video or video-on-demand; indeed the three terms are morphing into a single acronym - IPTV (Internet protocol television). ${ }^{4}$ One of the great advantages of IPTV and by definition, webcasting, is that it "can be supplied on any device that has Internet technology built into it, for example, desktop PCs, IP set-top 
boxes, games consoles, mobile phones, handheld devices, car stereos and media players. ${ }^{5}$ In whatever guise, they are often used in commercial organisations for the Chief Executive's pep talk to the staff, or for announcing the company's financial results simultaneously in the global financial centres. According to one survey, ' $90 \%$ of FTSE companies now use webcasting (up from $47 \%$ in 2001). ${ }^{6}$ Figure 1 is a screen shot of a webcast introducing an online course to undergraduate dental students.

\section{HITTING THE BUFFERS}

Although buffering may seem a hindrance, it actually provides one of the main advantages of webcasting in education. Buffering means the information is stored on the receiving terminal and can, therefore, be accessed on-demand at any time. As a result, students who are unable to see the original broadcast can view it later; similarly, they can return to it any time for clarification or revision.

The advantage of this for postgraduate students and those taking continuous professional development (CPD) courses with office hour schedules is clear. In addition it can allow practitioners in regional and rural hospitals and clinics to draw on the resources of major national centres as required.

\section{NOT JUST A TALKING HEAD}

Being only in 'quasi real-time' would seem to be a further disadvantage, as it would appear to negate any level of interactivity, one of the core benefits of videoconferencing. One authority has pointed out that 'they [webcasts] need to be supplemented with real-time, synchronous interaction to create a truly engaging synchronous interaction.'

The presentation does not have to be limited to a 'talking head' showing a number of PowerPoint slides. Using a split-screen arrangement, the slides can be shown simultaneously as a separate frame to the video; in another separate frame, a chat box for interaction such as asking questions of the presenter, or for discussion amongst students can be included. Webcasting can be further enhanced by facilities that introduce a high degree of interaction into a

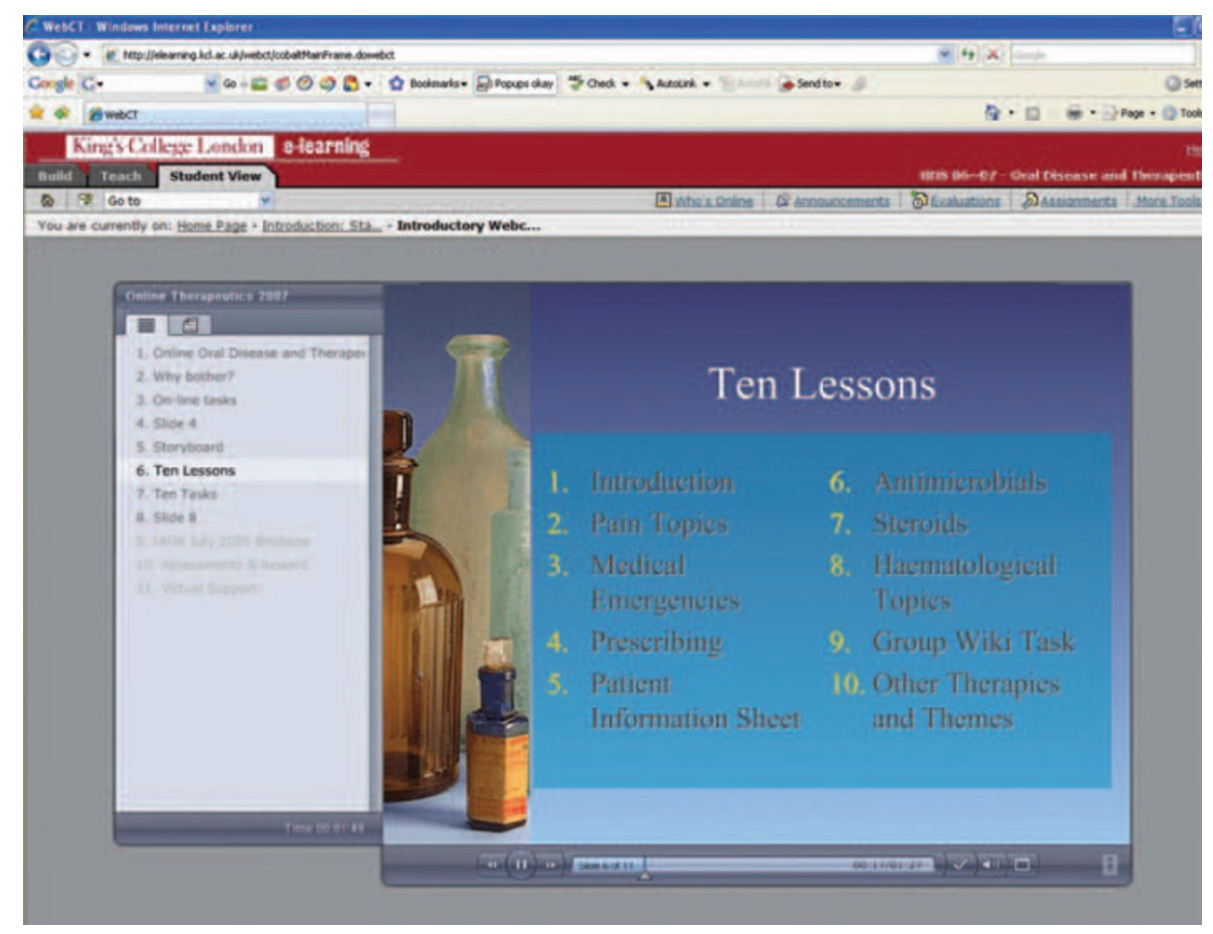

Fig. 1 Screen shot of an introductory webcast to an online oral disease and therapeutics course for dental undergraduates

presentation. A chat box is an example of this.

\section{PODCASTING}

The growing popularity of downloading music onto MP3 players, iPods or similar equipment is generating a potential interest in delivering lectures and other educational material via this method. Although at present primarily a music application, it should be remembered that it is a multimedia file on the internet that can be downloaded or streamed to a portable device and for playback on a mobile or PC.

This approach has been called ' $m$ learning': the signs are promising, as a senior lecturer in microbiology at Bradford University has discovered. ${ }^{8}$ Based on the observation that 'students were welded to their iPods, mobile phones and laptops, clearly studying while surfing the web', and the demand from overseas and dyslexic students for recorded lectures for note-taking and revision, his own lectures have been recorded and the audio distributed in a podcast format via Apple's iTunes. ${ }^{9}$

Student response has been very positive, as they can 'either download the lecture to their MP3 players or listen again on their computers or mobile devices at their convenience (24/7). ${ }^{9}$
The podcasts have subsequently evolved from just audio, to audio synchronised with slides, to video-podcasts.

Although just emerging in dentistry, the ability to download staff and students' educational podcasts from iTunes as part of a range of student tools is now available. $^{10}$ The following case studies illustrate studies already carried out in dentistry.

\section{CASE STUDIES}

\section{From videoconferencing to webcasting}

A webcasting project carried out at King's College London Dental Institute compared the use of videoconferencing (synchronous realtime audio and video communication) with webcasting and webcasting in different settings and with different presentations. ${ }^{3}$

\section{Methods}

The study was divided into three phases with progressively more complex screen components. These were applied to differing educational settings, including lectures, seminars and individual study. The three phases that were trialed were:

1. Videoconferencing and one-frame webcasting across a LAN (local area network) 
2. A two-frame webcast across the LAN, the second frame containing PowerPoint slides controlled by the student

3. A three-frame webcast across the Internet, the third frame acting as a live chat box. Alternatively, an on-demand recording of the webcast was made available on the Internet.

The students in Phase 1 were final year undergraduates in their last three months before qualification and were available on the campus, via the college LAN, when revision tutorials and lectures were being held. Phases 2 and 3 covered postgraduates within five years' of qualification: many were former students of the Institute; others were dental colleagues from the UK and overseas. They all had basic keyboard and Internet skills and had work or home Internet access.

The three phases allowed a natural progression from one-frame, LAN-based transmission in Phase 1 to two-frame transmission in Phase 2 and three frames in Phase 3. The Phase 1 frame contained both the 'talking head' and the PowerPoint slide.

The evaluation of the project was measured in a number of ways. First, a questionnaire was devised for the three phases, which focused on presentation features, technical factors and educational aspects. For the Phase 3 online version, an additional question regarding the material used in the on-demand webcasting was also prepared.

In addition the presenters made notes covering:

- Length of preparation

- Difference in delivery compared to conventional teaching

- Technical problems and assistance

- Communication and interactivity with remote sites

- Good, bad and unexpected points.

Subsequent interviews provided secondary data that clarified and explored comments already made or indicated emerging issues. For example, the visual aspect explored the picture clarity, refresh rate and value of image. The Phase 1 questionnaire was used as a checklist to ensure some degree of reliability, reproducibility and validity.

Table 1 Summary of the advantages and disadvantages of webcasting identified in case report 1

\begin{tabular}{|c|c|}
\hline FEATURE & COMMENTS \\
\hline Presenter effort & $\begin{array}{l}\text { Minimal preparation, but some complex interaction required. } \\
\text { Moderation may be needed. }\end{array}$ \\
\hline Comparison with lecture & $\begin{array}{l}\text { Much preferred; less threatening; available anytime and anywhere. } \\
\text { Lecturer need not be present if the delivery is on-demand. }\end{array}$ \\
\hline Variety of presentations & $\begin{array}{l}\text { Restricted and depending upon the number of frames and bandwidth. } \\
\text { Can include video, audio, slides, notes and chat. }\end{array}$ \\
\hline Cost & $\begin{array}{l}\text { Free to user unless fee-paying. Can be free to broadcaster. Costs depending } \\
\text { on scale and complexity amount to a few thousand pounds. }\end{array}$ \\
\hline Sound quality & Preserved above all else; usually clear \\
\hline Picture quality & $\begin{array}{l}\text { Video can be jerky and out of synchronisation. Slides may be slow to load } \\
\text { or unclear. }\end{array}$ \\
\hline Interactivity & $\begin{array}{l}\text { Can be complex depending on elements on the screen. There is time to } \\
\text { reflect and a live or on-demand facility. }\end{array}$ \\
\hline User friendliness & Simple for users and presenters, but typing skills needed. \\
\hline Educational value & Rated very good; can be linked to virtual classroom. \\
\hline Best points & $\begin{array}{l}\text { Multiple activities; links to online classroom; global, low-cost and } \\
\text { simple access. }\end{array}$ \\
\hline Worst points & Bandwidth restrictions; relatively poor video transmission. \\
\hline Special aspects & $\begin{array}{l}\text { Globally available in time and space; only requires a computer and browser; } \\
\text { verifiable access. }\end{array}$ \\
\hline
\end{tabular}

Each in-house session was videotaped by a member of staff who also acted as an observer. The following checklist structured the observations:

- The environment

- Seating plan

○ Overall atmosphere (enthusiasm/ disinterest)

- Broadcast clarity

- Participants

- Involvement, eg seeking/proffering information

- Disagreeing or supporting actions

- Need for support and type

- Interaction with presenter and peers (proposing and building)

- Other events.

\section{Results}

In the one-frame webcast, the lack of opportunities for interaction, especially in comparison with videoconferencing, was commented upon. In Phase 3 the addition of a chat box was much appreciated. This phase also included the capability of streaming out to the Internet to reach postgraduate dental students at home or work, which enabled remote participation from as far as Australia.

The potential value of such an Internet link for webcasting and other forms of distance learning is shown by the fact that by December 2006, 'over 70\% of all UK homes and 90\% of all UK businesses are now broadband enabled. ${ }^{5}$ The connections vary in terms of connection speeds, with the higher capacities providing the quality and speed to ensure webcasting with the best possible resolution without the transmission delays that produce picture jerkiness.

Table 1 is a summary of the advantages and disadvantages of webcasting emanating from this research.

\section{Responses}

A key response from students was their support for the review and the ability to replay a webcast in their own time, allowing them to participate at any time and from anywhere as well as enjoying a live webcast. This is important as, for example, a snapshot of the final year representing the new generation of postgraduates had Internet access $84 \%$ of the time at home and always at college. The ability to gain verifiable training simply and at low cost by webcast is another important feature.

Webcasting scored high in the presentational and educational areas, and with technical difficulties identified (mainly bandwidth restriction which, with the recent launch and growing availability 
of DSL broadband services, is being overcome), should score highly in the future. The key advantages were those of:

- Anytime, anyplace viewing

- The possibility of embedding webcasting in online courses

- The opportunities of interaction without embarrassment and with time to review the answer

- The ability to replay 'on-demand'.

In addition, sophisticated pedagogically-designed content can be presented to the student that can include assessments and quizzes.

Access to webcasts was inexpensive, available from home and worked well in one-to-one settings and seminars. In the latter it could be also be used as a point of discussion while webcasts could be projected to a lecture audience, much in the same way as a videoconference is managed.

In pedagogical terms webcasting tends to be 'constructivist', in part due to the nature of the delivered content and in part due to its interactivity. It appears to have a more cognitive aspect and be more student-centred than videoconferencing, with the students being more active.

In the three-frame webcast run as an on-demand lecture in Phase 3, three final year students were in a remote room chatting to the lecturer in the main lecture theatre. The students controlled the slide change in the lecture theatre. Observational study demonstrated that the students were totally engrossed in the proceedings and the questionnaires revealed that nearly all of the ratings for the event were very good. As there were no bandwidth problems or net congestion, the sound and vision were highly graded while the interactivity ratings soared and were almost all very good. The presenter felt totally under control and hardly had to utter a word except in e-moderation. Interviews revealed that the students enjoyed the sessions immensely and demonstrated it to friends, colleagues and relatives subsequently from their own computers.

\section{Conclusions}

The project showed that webcasting could be used in all the three scenarios

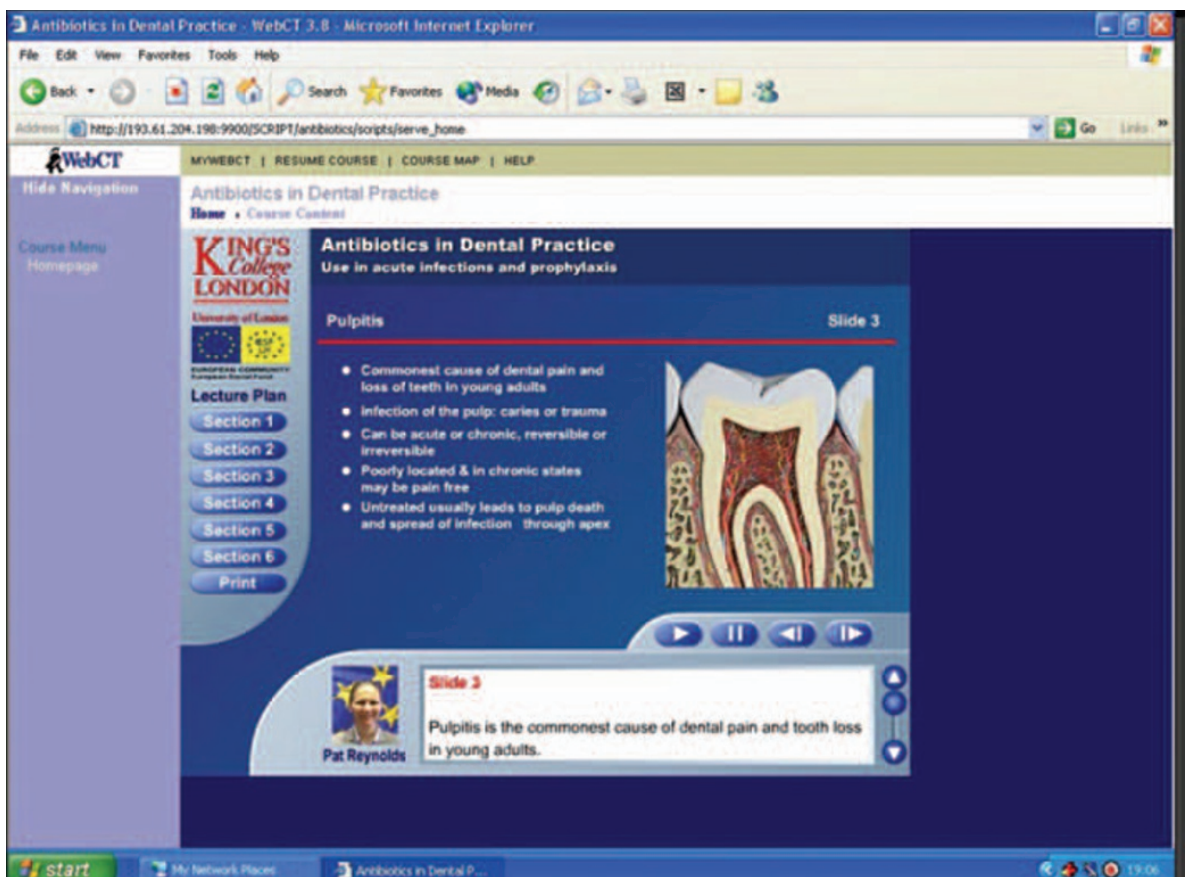

Fig. 2 Screen shot of a more sophisticated webcast used for both dentists and pharmacists

tested (lectures, seminars (webinars) and individually), but it was best suited to the one-to-one setting where students are working in their own space, place and time. Other key points:

- In the lecture setting, a webcast can either completely replace the event (much desired by students) or reinforce the lecture with a replay option online. It can also be projected when a lecturer is remote (live) or simply unavailable (on-demand)

- It does not make extra demands on the presenter and set-up times are minimal

- Webcasting is popular because it contains 'interactive' elements and is widely available anytime and anywhere, although continuity of audio is important

- A design of no less than three frames is preferred, ie one each for video, slides and chat. Students prefer webcasting to traditional lectures because of active and non-threatening participation. They like the potential of on-demand access and links to online courses

- Webcasting can be further developed by employing a professional production consortium where the GDP pays for the courses - or by the use of bespoke software with good bandwidth where the student receives it free.

\section{Additional learning points}

The design of the screen presented to students appears to have an important impact on the success of webcasting. Although it can be complex, it should not be so overloaded that students become overwhelmed. As with good web design, a series of lectures should be in a standard format with sensible colours, good definition and easy navigability. Given that the bandwidth is available, interactive elements are essential. The talking head adds a personal and character touch to the event and can initiate and answer questions posed in the chat box. Text must be of sufficient size to be read and slides should be as large as possible to remain clear. From experience, students like to be able to change the slides and even download them as handouts for review later. PowerPoint slides, for instance, can be shown in full-screen format if desired.

Quality webcasting, like any form of professional broadcasting, requires a team to create content, promote the event and execute it. ${ }^{1}$ On a smaller scale, templates can be produced for the nontechnically minded to drop in their slides or images and then start talking. Such presentations can be recorded for on-demand use. There is no doubt that, with accredited courses provided by dental schools or by industry, all dentists with a computer at home, in their practice or anywhere globally will be 
able to receive good quality webcasting as part of CPD.

\section{Delivery of continuing profes- sional development in the work- place to pharmacists and dentists}

\section{Introduction}

This project enabled a series of webcasts to be created for transmission across the internet to 50 pharmacies and dental practices. ${ }^{11}$ The project extended the work of the previous case study in the area of CPD and developed more sophisticated webcasts that were made available to both pharmacists and dentists within a virtual learning environment (Web Course Tools (WebCT)) (Fig. 2).

\section{Methods}

A survey of the participating practices enabled a short list of webcasts to be prepared for use in CPD. These included:

- Medicines management

- Medical emergencies

- Antibiotics

- Clinical governance

- Good communications

- Vitamins and minerals

- Acupuncture and hypnosis.

The webcasts were developed in a variety of rich media formats and included a combination of audio, video and animated diagrams with online interactivity within the virtual learning environment (VLE) WebCT. Flash MX (http://www.flash-mx.com) was chosen as the preferred authoring program as it combined all the elements of interactivity and media and compressed it for webcasting to dial-up bandwidths.

The webcast topics were streamed over the Internet with lecture notes and illustrations. These were available 24 hours a day, seven days a week to ensure flexibility of access.

Each programme delivered accredited CPD that could be used towards the development of a personal CPD portfolio. Participants were invited to complete all packages and evaluation questionnaires online and were interviewed towards the end of the project. The results were analysed using mainly qualitative methodology supported by three LTSNs (learning and teaching support networks).

\section{Results}

Participants reported that the website was indeed a very interesting way for the delivery of their CPD and enjoyed accessing the programmes. The main barrier to completion of the packages was the availability of time to complete the programmes and the longer loading times when dial-up access was used.

Following a live webcast in which ten pharmacists participated, it was reported that this was a very valuable activity. They did not need a 'talking head' provided that the audio was preserved. Improvements in webcasting technology during the course of the project enabled enhanced server delivery and improved interactivity and screen presentation. This was much appreciated by dental practices and pharmacies whose internet access was mainly by dial-up connectivity at this time.

\section{Conclusions}

The use of web-based interactive educa- tional resources using a variety of rich media was considered a useful way of accessing CPD by professionals in busy dental practices and pharmacies. The webcasts continue to be used for undergraduate dental education. As broadband technology is now pervasive and the delivery of CPD online becomes more widely accepted, high quality webcasts will be ever more available for delivery online or by other delivery methods such as podcasts.

1. Richardson W. Blogs, wikis and podcasts and other powerful tools for classrooms. London: Sage Publications Ltd, 2006.

2. Scott P, Eisenstadt M. Exploring telepresence on the Internet - the KMI stadium webcast experience. In Eisenstadt M, Vincent T (eds) The knowledge web. London: Kogan Page, 1998.

3. Reynolds P A, Mason.R. On-line video media for continuing professional development in dentistry. Comput Educ 2002; 39: 65-98.

4. School district adds streaming video system The metropolitan School District of Warren Township integrates a cost-effective video capture and distribution system on its fiberoptic infrastructure. AV Magazine 2006 (December) www.proavmagazine.com (accessed 27 January 2008).

5. Cameron A. All you need to know about IPTV. AV Magazine 2006 December.

6. Joy A. Users sign up to IPTV. AV Magazine 2006 December.

7. Reference 7 - Stacey P.E. Learning for the B-TECH Industry on t-net. $t$-net British Columbia 2004 www.bctechnology.com (accessed at 27 January 2008).

8. Clapperton G. More than just idle talk. The Guardian (London) 2006 October 27.

9. Ashraf B. Lecturer adds value with iTunes. The Guardian (London) 2006 December 12.

10. Outstanding ICT initiative of the year. In The winners. The Times Higher Awards 2007. pp 18. The Times Higher Education Supplement (London) 2007 December. http://www.thes.co.uk/ upload/2039270/THS_awards_2007.pdf (accessed 15 December 2007).

11. Jones S, Reynolds P A. Development of a webbased approach to learning to fulfil continuing education needs of pharmacists. (Abstract and Workshop \#3). 6th International Conference on Life Long Learning in Pharmacy, University of Saskachewan, Saskatoon, Canada. June 26-29, 2005. http://www.Illp.usask.ca/program/abstracts. php\#w1 (accessed 11 November 2006). 